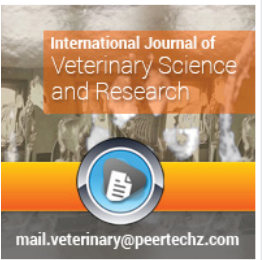

Life Sciences Group

\title{
International Journal of Veterinary Science and Research
}

Bamlaku Andarge ${ }^{1}$, Chaltu Muhammed ${ }^{1}$ and Gebawo Tibesso ${ }^{2 *}$

'Livestock and Fisheries development office, Ethiopia ${ }^{2}$ Oromia Agricultural Research Institute, P.O.Box 229, Batu, Oromia, Ethiopia

Dates: Received: 02 August, 2017; Accepted: 18 September, 2017; Published: 19 September, 2017

*Corresponding author: Gebawo Tibesso, Oromia Agricultural Research Institute, P.O.Box 229, Batu, Oromia, Ethiopia, Tel: +251912152764; E-mail: nadhi2521@yahoo.com

https://www.peertechz.com
Research Article

\section{Prevalence of Major Intestinal Nematodes of Equines in Jimma Town, South Western Ethiopia}

\section{Abstract}

A cross sectional study was conducted from October, 2015 up to March, 2016 in Jimma town, Oromia Regional State of South West Ethiopia, with the objective of determining the prevalence of intestinal nematode parasites of equines and the effect of putative risk factors on the rate of helminth parasite infections. A total of 400 Equines; donkeys $(n=29)$, horses $(n=317)$ and mules $(n=54)$ were included in the study. Out of 400 faecal samples examined, three species of nematode eggs were identified during the study period. Coprological examination conducted using flotation technique revealed an overall point prevalence of $72.25 \%$. The most common nematodes encountered in order of their predominance were, Strongyles (63.25\%), Parascaris equorum (16.5\%), Oxyuris equi $(4.25 \%)$, and mixed infection was found to be $(10.75 \%)$. The results of statistical analysis of different risk factors with risk of intestinal nematode infection indicates a significant difference $(P<0.05)$ between the species of equine and strongyle infection rate, body condition scores with Strongyle and Parascaris equorum infection rate. But species of the animal was not significantly associated with Parascaris equorum $(P<0.05)$. The infection rate of Oxyuris equi was not significantly associated with body condition score, age and species of equines $(P>0.05$ for all variables). Statistical analysis of the result also showed no significant difference $(p>0.05)$ in the prevalence of intestinal nematodes with sex of the animal, although it was relatively higher in male than female individuals. Therefore, the present study showed that intestinal nematodes are an important health problem in the area affecting the wellbeing and productivity of the equines.

\section{Introduction}

Despite the increase in mechanization in the world, donkeys, horses and mules are still well deserving of the name "beats of burden". They have a prominent position in agricultural system of many developing countries. This is shown by the wide spread use of equines in rural and urban areas of Africa [1,2]. The world equine population is about 122.4 million consisting of $43.4,40$ and15 million horses, donkeys and mules respectively. Out of the global distribution $98 \%$ of donkeys, $97 \%$ of mules and $60 \%$ of horses are distributed in the developing countries. The equine population in Africa is $\mathbf{1 7 . 6}$ million, consisting of $\mathbf{1 1 . 6}$ million donkeys, 3.7 million horses and 2.3 million mules [3,4].

Ethiopia possesses nearly half of African equine population with $58 \%, 46 \%$ and $37 \%$ of all horses, mules and donkeys respectively [5]. Equines are important animals to the resource poor community in the rural and urban areas of Ethiopia providing traction power and transport service at low cost. In the farming system of Ethiopia, equines play a vital role in both economic as well as social functions. They are kept and are often used for land tillage, cultivation, and threshing, as well as for pack purposes, riding, Social security, prestige and providing of manure for both energy and soil fertility [5].

Parasitic diseases, dominated by gastrointestinal parasites, are serious health hazards, contributing to poor body condition, reduced power output, poor reproductive performance, retarded growth and short lifespan of equines [6]. Large number of internal parasites has been reported to occur in six African countries including Ethiopia, Kenya, Zimbabwe, Burkinafaso, Chad and Morocco [7].

Many intestinal nematodes (round worms) occur in equines, which includes large strongyles (Strongylus vulgaris, Strongylus equinus, Strongylus edentatus and triodontophorous species), Parascaris equorum, Oxyuris equi and to the lesser extent other small strongyles (cyathostomins) [8]. Clinical illness occurs not only from the presence of the adult parasite in the intestine, but also from larval migration in the intestinal wall and other organs, notably the circulatory system, however they may also found in the intestine of most equines without signs necessarily being observed $[9,10]$. 
Infection occurs from ingestion of infective larvae or egg during grazing. Virtually all grazing horses infected with this parasite but many low to moderate infection are sub-clinical, although they may cause reduced weight gain and performance [11]. Young non-immune animals are most susceptible to clinical disease, which may include diarrhoea, colic and hypoproteinemia [12]. Diagnosis of most intestinal nematodes of equines is possible by demonstration of eggs of the parasites from faecal samples. These parasites are susceptible to common deworming agents like Ivermectin, Moxidectin mebendazole, pyperazine etc. Generally, infection with intestinal nematodes can result in reduction of productivity of equines because of weakness, colic diarrhea, pruritis and intestinal obstruction [6].

Although there are some researches carried out in certain parts of the country, on equine helmenthosis, it has not been done in the study area so far. Therefore, this study is targeted to fill the information gap in the area with the following objectives:

- To estimate the prevalence of intestinal nematodes of equines in Jimma town.

- To assess the potential risk factors of infection for intestinal nematodes in equines.

Significance statement: This study discover the type of parasite that affect equine that can be beneficial for government organization and other institutions that are engaged on disease prevention and control.

\section{Materials and Methods}

\section{Study Area}

The study was conducted at Jimma town, South Western Ethiopia. Jimma town is located in Oromia regional state administration; $352 \mathrm{~km}$ Southwest of Addis Ababa. The town is located at latitude of about $7^{\circ} 13^{\prime}-8^{\circ} 56^{\prime} \mathrm{N}$ and longitude of about $35^{\circ} 52^{\prime}-37^{\circ} 37^{\prime} \mathrm{E}$ and at elevation ranging $880-3360$ meter above sea level. The area receives a mean annual rainfall of about $1530 \mathrm{ml}$, which comes from the long and short rainy seasons. The annual minimum and maximum temperature is about $14.4^{\circ} \mathrm{C}$ and $26.7^{\circ} \mathrm{C}$ respectively [13] (Figure 1).

\section{Study Population}

A total of 400 equines from Jimma town were subjected to qualitative coprological examination to determine the prevalence of major intestinal nematode species of equines, Out of which, horses, mules and donkeys comprised $79.25 \%$ (317), 13.5\% (54) and 7.25\% (29) respectively. All age and sex groups of local origin equines were included in this study and equines less than 5 years of age were considered as young, while those more than 5 years old as adults conventionally. Even though determination of age range was done conventionally, estimation of ages of equines was by using history of the animal

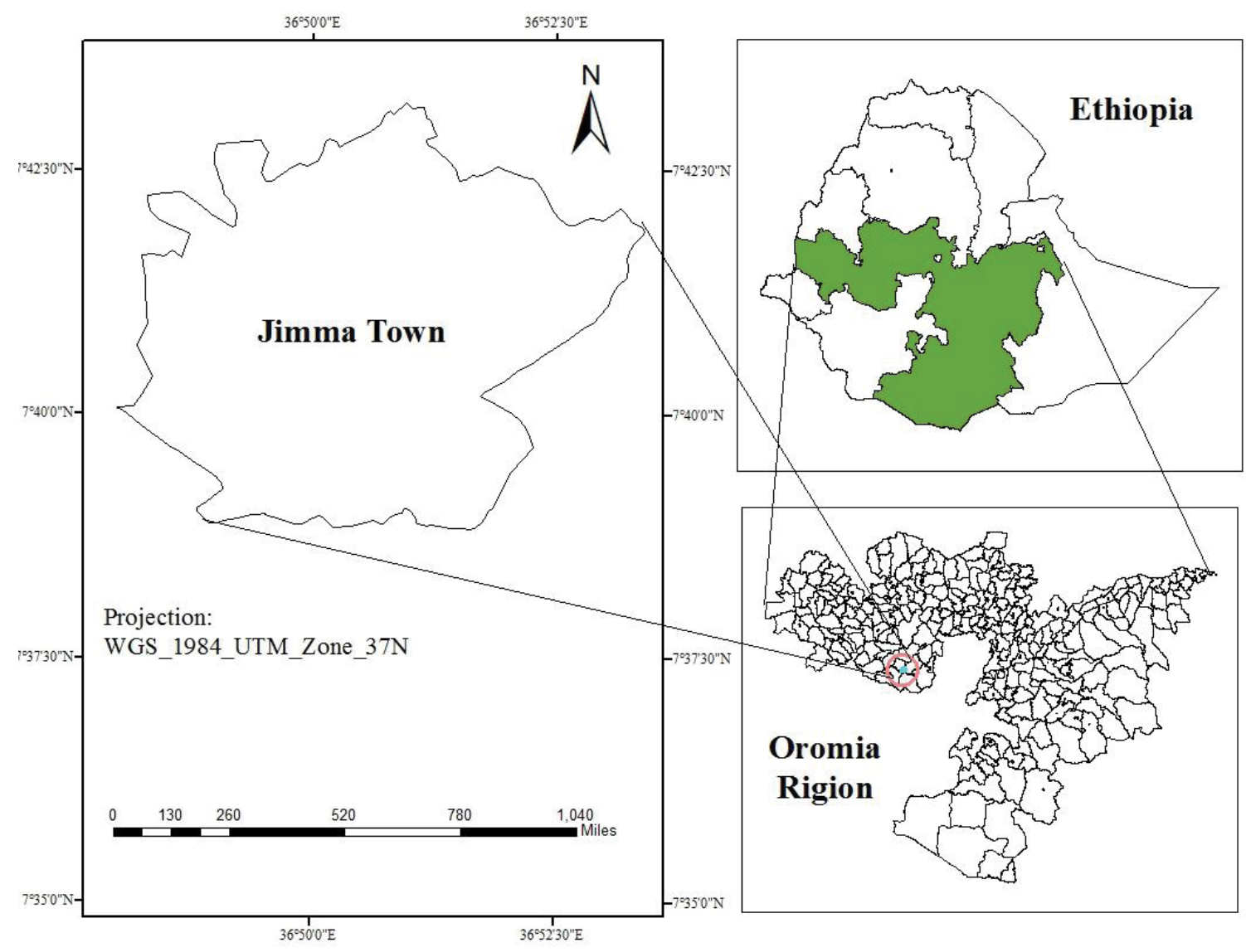


and guideline of age estimation by dentition as stated by David (2002). Linear body condition score grading were taken using pictorial guideline of IDPT trial (1985). Clinical examination using visual inspection and physical assessment were done on each equine.

\section{Study design}

A cross-sectional study was carried out to determine the Prevalence of Major Intestinal Nematodes of Equines in Jimma Town from October, 2015 up to March, 2016. Purposive sampling was employed to select kebeles and households keeping horse in Jimma town followed by simple random sampling to select study animals from the selected households. Kebeles and households were purposively selected based on accessibility, population of the study animals and willingness of the owners to be involved in the survey.

\section{Coprological Examination}

Faecal samples were collected directly from the rectum of each animal or during defecation with strict sanitation, in plastic bottles labeled with identification number and then brought to the laboratory. In the laboratory the samples were subjected to saturated sodium chloride flotation method of faecal examination technique to identify eggs of intestinal nematodes of equines such as strongyle species, P. equorum and 0 . equi. The flotation technique was conducted as the procedure given by William, 2001 [14].

- Approximately $3 g$ of faeces was placed in a beaker.

- Then $50 \mathrm{ml}$ of floatation fluid was poured into the beaker containing $3 \mathrm{~g}$ of faeces and mixed thoroughly.

- The resulting faecal suspension was poured through a tea strainer into another beaker.

- Then the faecal suspension was poured into a test tube from the second container.

- The test tube was placed on the test tube rack.

- Then the test tube was gently filled with the suspension leaving a convex meniscus at the top of the tube and a cover slip was carefully placed on the top of the test tube.

- Then the tube was allowed to stand for 20 minutes.

Finally the cover slip was lit off carefully from the tube vertically, together with the drop of fluid adhering to it, and immediately placed on microscope slide and examined under the microscope.

\section{Data Management and Analysis}

The collected data from the field were stored in to a computer on a Microsoft excel spreadsheet and analyzed using SPSS version 20 software program. The prevalence was calculated as the number of animals having parasite, divided by the total number of animal examined. The association between the risk factors and the outcome variables was assessed using chi-square $\left(x^{2}\right)$ test. For all analysis, a P-value less than 0.05 were taken as significant.

\section{Result}

From a total of 400 faecal samples examined, 289 samples were positive for one or more eggs of the major intestinal nematodes of equines, indicating that the overall prevalence was $72.25 \%$ (Table 1 ). Three types of nematode eggs were identified during the study period, based on their morphology, as described by Soulsby [15]. The cumulative prevalence of Strongyle, $P$. equorum and $O$. equi in equine species was observed to be $63.25 \%, 16.5 \%$ and $4.25 \%$ respectively.

Prevalence of strongyles in horses, mules and donkeys was $63.72 \%, 51.85 \%$ and $79.31 \%$ respectively, and there was a significant differences $(\mathrm{p}<0.05)$ between the species of equine with respect to susceptibility to the parasite. According to this study age and sex are not significantly associated with the occurrence of strongyle infection ( $p>0.05)$ for both variables. Rate of infection with strongyles in poor, medium and average body condition scores of equine species was $86.90 \%, 61.15$ and $37.50 \%$ respectively (Table 2 ) and there was a highly significant variation $(\mathrm{p}=0.001)$ between body condition score and presence of the parasite egg in the feaces of equines.

The Prevalence of P. equorum in horses, mules and donkeys in the study area were found to be $17.98 \%, 12.96 \%$ and $6.89 \%$ respectively and there was no significant difference between species (Table 3). The difference in the prevalence of P. equorum between different age groups and sexes was not significant (P>0.05). But the Prevalence of Parascaris equorum in different BCS of animals was found statistically significant $(\mathrm{P}<0.05)$ This indicated that as the animal gets emaciated the immunity is not active enough to prevent the disease condition.

The prevalence of Oxyuris equi based on species, age, sex, and body condition score is indicated below in tables 4 and there was no significant variation ( $p>0.05$ for all variables) between the variables and occurrence of the disease.

Table 1: Overall prevalence of equine Intestinal nematodes in equine species basis.

\begin{tabular}{|c|c|c|c|}
\hline Species of Animal & N & positive & \% positive \\
\hline Horse & 317 & 234 & 73.81 \\
\hline Mule & 54 & 32 & 59.25 \\
\hline Donkey & 29 & 23 & 79.31 \\
\hline Over all & $\mathbf{4 0 0}$ & $\mathbf{2 8 9}$ & $\mathbf{7 2 . 2 5}$ \\
\hline
\end{tabular}

Table 2: Chi-square analysis of the association of different risk factors with Strongyle infection.

\begin{tabular}{l|l|l|l|l|} 
Risk factor & Number of animals & $\%$ positive & X2-value & P-value
\end{tabular}

\begin{tabular}{|c|c|c|c|c|c|}
\hline Species & Horse & 317 & 63.72 & 6.26 & 0.04 \\
& Mule & 54 & 51.85 & & \\
\hline \multirow{2}{*}{ BCS } & Donkey & 29 & 79.31 & & 0.00 \\
& Poor & 84 & 86.90 & 36.68 & \\
& Medium & 260 & 61.15 & & \\
\hline \multirow{2}{*}{ Age } & Good & 56 & 37.50 & & 0.52 \\
& young & 12 & 66.66 & 1.29 & \\
\hline \multirow{2}{*}{ Sex } & Adult & 388 & 61.25 & & 0.23 \\
& Male & 241 & 61.41 & 0.88 & \\
\hline
\end{tabular}




\section{Discussion}

Nematode parasites are serious health hazards of equines, contributing to poor body condition, reduced power output, poor reproductive performance, retarded growth and short lifespan of equines. This study showed that strongyle type nematodes were significantly higher than other detected nematodes. Accordingly it has revealed prevalence of strongyle species (63.25\%) Parascaris equorum (16.5\%) and Oxyuris equi (4.25\%) infection in equines, which is relatively lower, as compared to some studies conducted at different geographical location, such as Belay (2011), who reported a prevalence of $100 \%, 39.77 \%$ and $22.88 \%$ respectively, in South and North Wollo zone. However it is in agreement with work done by Sinasi and Mustafa (2009) who reported prevalence of $P$. equorum (14.45\%) and 0 . equi $(4.82 \%)$ and Sotiraki, (1997) who reported the prevalence of strongyles $64 \%$. The prevalence of strongyles was significantly higher $(\mathrm{P}=0.04)$ than that of $P$. equorum and 0 . Equi and this may be due to the reason that strongyles are studied to genus level and contains many species occurring in equines.

Low infection rates of this study might be attributed to sensitivity of diagnostic technique or difference in agro ecological zones of the areas. This idea is supported by Chaudhry et al. [16], who presented the effect of diagnostic techniques and difference in the agro-ecological zones of the study area in the prevalence of nematode parasites of animals. Some other factors like management, climate and parasite control Program can also influence the prevalence of parasites of domestic animals. Use of broad spectrum anthelmintics like benzimedazoles and macrocyclic lactones has resulted in drastic reduction in worm populations of large strongyles

Table 3: Chi square analysis of the association of different risk factors with Parascaris equorum infection.

\begin{tabular}{|c|c|c|c|c|c|}
\hline \multicolumn{2}{|c|}{ Risk factors } & Sampled animals (No) & \% positive & X2-value & P-value \\
\hline Species & Horse & 317 & 17.98 & 2.93 & 0.23 \\
& Mule & 54 & 12.96 & & \\
& Donkey & 29 & 6.89 & & \\
\hline \multirow{2}{*}{ BCS } & Poor & 84 & 28.57 & & \\
& Medium & 260 & 14.61 & 13.11 & 0.01 \\
& Good & 56 & 7.14 & & \\
\hline \multirow{2}{*}{ Age } & Young & 12 & 16.66 & 1.65 & 0.43 \\
& Adult & 388 & 16.49 & & \\
\hline \multirow{2}{*}{ Sex } & Male & 241 & 19.08 & 2.94 & 0.56 \\
& Female & 159 & 12.57 & & \\
\hline
\end{tabular}

Table 4: Chi square analysis of the association different risk factors with Oxyuris equi infection.

\begin{tabular}{|c|c|c|c|c|c|}
\hline \multicolumn{2}{|c|}{ Risk factor } & Sampled animals (No) & $\%$ positive & $\chi^{2}$-value & P-value \\
\hline pecies & $\begin{array}{c}\text { Horse } \\
\text { Mule } \\
\text { Donkey }\end{array}$ & $\begin{array}{c}317 \\
54 \\
29\end{array}$ & 5.041 .850 & 2.54 & 0.28 \\
\hline BCS & $\begin{array}{l}\text { Poor } \\
\text { Medium } \\
\text { Good }\end{array}$ & $\begin{array}{c}84 \\
260 \\
56\end{array}$ & $\begin{array}{c}8.333 .07 \\
3.57\end{array}$ & 4.38 & 0.11 \\
\hline Age & $\begin{array}{l}\text { Young } \\
\text { Adult }\end{array}$ & $\begin{array}{c}12 \\
388\end{array}$ & 04.25 & 0.54 & 0.76 \\
\hline Sex & $\begin{array}{c}\text { Male } \\
\text { Female }\end{array}$ & $\begin{array}{l}241 \\
159\end{array}$ & 4.563 .77 & 0.15 & 0.70 \\
\hline
\end{tabular}

$[17,18]$. One last possible cause of the lower prevalence of this study may be origin of the animals, because all the animals included in the study were from Jimma town, where relatively better awareness to animal diseases and better access to anthelmintics is present, unlike study of Belay, which is conducted on equines from different rural areas of Wollo zone. Higher infection rates are reported in animals examined by post mortem examination [19], and Studies based on necropsy findings have better chance to diagnose many latent infections that are missed at coprological examination $[20,19]$.

The prevalence of strongyles was $63.72 \%, 51.85 \%$ and $79.31 \%$ in horses, mules and donkeys respectively and there was a significant differences $(\mathrm{p}<0.05)$ between the species of equine with respect to susceptibility to the parasite. This result was in agreement with Saeed et al. [21], and Cirak and Gulegen [22], who reported $58.50 \%$ and $68 \%$ prevalence of strongyles in horses, in Lahore, and western Turkey respectively. According to this study there was no significant variation ( $p>0.05)$ between the two age groups (young and adult) in susceptibility to the parasite. This may be attributed to the less number of young animals included in the study. Prevalence of strongyle species among equines with poor, medium and good body condition scores was $86.90 \%, 61.15 \%$ and $37.50 \%$ respectively and the deference between body condition score and presence of the parasite egg in the feaces was highly significant $(\mathrm{p}<0.001)$. This significant association was evidenced from quantitative faecal egg analysis; animal with lower infection had relatively good body condition as Shiferaw [23].

The Prevalence of P. equorum in horses, mules and donkeys in the study area were found to be $17.98 \%, 12.96 \%$ and $6.89 \%$ respectively, and there was no significant difference between species. Similarly Shiferaw et al. [24], had reported $12.9 \%$, $13.6 \%$ and $15.7 \%$ prevalence of P. equorum in horses, mules and donkeys of Wonchi, respectively. However, prevalence of the present study is lower, as compared to the study of Belay [25], who reported $36.02 \%, 28.3 \%$ and $43.8 \%$ in South and North Wollo zones, respectively. The lower finding of the present study might be due to the difference in the age of examined animals. Equines commonly develop marked resistance to $P$. equorum after six months of age [19].

The prevalence of 0 . equi was $5.04 \%, 1.85 \%$ and $0 \%$ in horses, mules and donkeys respectively. This result is comparable with the result of Sotiraki [26], who reported the prevalence $4.1 \%$ and Sinasi and Mustafa [27], who reported $1.20 \%$, in horses. The reason for the low rate of infection of 0 . equi might be a consequence of not using transparent tape for diagnosis purpose. 0 .equi eggs are rarely found on faecal examination of samples taken from the rectum but may be observed in materials from the perineum or in faecal materials taken from the ground [28]. There was no significant variation ( $p>0.05$ ) between the variables and occurrence of the disease.

\section{Conclusions}

The present study conducted on equines intestinal nematodes in Jimma town of Oromia regional state showed that intestinal nematodes are an important health problem in the area affecting the well-being and productivity of the 
equines. However, the attention given to the disease so far has not been sufficient. Even though, equines are paramount important animals in farming system of the country, the existing livestock extension package program of the region and the country is saying nothing about the management and health aspect of equines.

\section{Recommendations}

Based on the above conclusion the following recommendations were forwarded:

- To get clear epidemiological picture of parasitic helminthes, comprehensive study should be launched in the area.

- Strategic treatment with appropriate, effective and broad spectrum anthelmintics should be practiced at the beginning and after the end of rainy seasons.

- The government should formulate an appropriate policy regarding equines' management and health aspects without delay, and this should be hold in the livestock extension package program.

- Additionally, the field veterinarians and stockowners should be aware of the importance and burden of helmenthosis in equines.

\section{References}

1. Pearson RA, Nengomasha $E$, kreck RC (1999) The challenges of using donkeys for work in Africa, London 190-198. Link: https://goo.gl/nXF4rw S

2. Bowman's DD (2003) Parasitology for veterinarians. $8^{\text {th }}$ ed. New York: Saunders 155-184. Link: https://goo.gl/FCrjjh

3. Fielding D (1991) The number and distribution of equines in the world, UK 62-66. Link: https://goo.gl/krf6Dr

4. Taylor MA, Coop RL, Waller RL (2007) Veterinary parasitology. $3^{\text {rd }}$ ed. United Kingdom: Black well publishing. 272-286. Link: https://goo.gl/HJ9sdw

5. Elisabeth D, Sevendesen MBE (1997) Professional donkey hand book, London: anleyroad. 61-67.

6. Foreyt JW (2004) Veterinary parasitology reference manual, $1^{\text {st }}$ ed. London black well, 117-119.

7. Pandey VS, Khallaayoune K, Ouhelli H, Dakask A (1994) Parasites of Donkeys in Africa. Proceedings of the second colloquium on working equines .Institute Agronomique Veterinaire Hassan II, Rabat, Morocco, 35-44. Link: https://goo.gl/euCWMy

8. Radostitis OM, Blood OC, Gay CC (2007) A text book of the disease of cattle, sheep, goats, pigs and horse: Veterinary medicine $10^{\text {th }}$ ed. UK: Baillere, Jindall, 1570-1584. Link: https://goo.gl/z82JDL

9. Wintzer JH (1996) Equine diseases. $2^{\text {nd }}$ ed. Verlap Paul. 141-145. Link: https://goo.gl/P4P7X8

10. Donald HB (2001) Equine parasitology: The control of gastrointestinal nematode $\mathrm{h}$ parasites in horses with Emphasis on Reducing Environmental Contamination. Mid America Agricultural Research, Verona, WI. 17-21.
11. Smith BP (2009) Large animal internal medicine. $4^{\text {th }}$ ed. USA: Elsevier. 1623 -1627. Link: https://goo.gl/m4kYfw

12. Zajac MA, Conboy AG (2006) Veterinary clinical parasitology. $7^{\text {th }}$ ed. London: black well. W67-72. Link: https://goo.gl/czEoFD

13. BoA (2015) Oromia regional state, Bureau of agriculture, Annual report Jimma.

14. William JF (2001) Veterinary parasitology: A reference manual. $5^{\text {th }}$ ed Blackwell. 214-222. Link: https://goo.gl/CHCmtD

15. Soulsby EJL (1982) Helminths, Arthropods and Protozoa of Domesticated Animals: $7^{\text {th }}$ ed. London: Baillere Tindall 239. Link: https://goo.gl/U3KDem

16. Chaudhry, Sohail AHE, Iqbal Z (1991) Studies on the prevalence and taxonomy of the members of genus Strongylus and their effect on blood picture in equines in Faisalabad Pakistan: Pakistan Veterinary Journal 11: P179 - 181. Link

17. Konigova, Varady AM, Corba J (2003) Comparison of in vitro methods and faecal egg count reduction test for the detection of benzimedazoles resistance in small strongyles of Horses. Veterinary Research Communications 27: 281 288. Link: https://goo.gl/F75GEg

18. Love S (2003) Treatment and prevention of intestinal Parasite- associated disease. Veterinary Clinics of Equine. 19: 791-806.

19. Boxell, Gibson, Hobbs RP, Thompson RCA (2004) Occurrence of gastrointestinal parasites in horses, in metropolitan Perth, Western Australia. Australian Veterinary journal 82: 91 - 95. Link: https://goo.gl/tTAJoH

20. Chapman, French MR DD, Klei TR (2002) Gastrointestinal Helminths of equines in Louisiana: a comparison of species currently prevalent with those present 20 years ago. Journal of Parasitology 88: 1130 - 1134. Link: https://goo.gl/ohkdnX

21. Saeed K, Qadir Z, Ashraf K, Ahmad N (2010) Role of intrinsic and extrinsic epidemiological factors of strongylosis in horses. The Journal of Animal \& Plant Sciences 20: 2010: 277-280. Link: https://goo.gl/AR9zqd

22. Cirak VY, Gulegen E (2005) The prevalence of strongyle infections and persistent efficacy of pyrantel embonate, Ivermectin and Moxidectin in Turkish horses. Turkish Journal of Veterinary and Animal science 29: P29 175-181. Link: https://goo.gl/dKb87T

23. Shiferaw Y, Alemayehu M, Smith GD, Terefe F, Shelima B, et al. (2011) Helminth parasites of donkey in Western and East shoa zones, central Ethiopia. Ethiopian Veterinary Journal P 4-9.

24. Shiferaw Y, Gebreab F, Wesene A (2001) Survey on helmenthosis of equines in Wonchi. Journal of Ethiopian Veterinary Association 5.

25. Belay M (2011) Preliminary study on helmenthosis of equines in south and north Wollo zones, Kombolcha regional veterinary laboratory, Kombolcha.

26. Sotiraki ST, Badouvas AG, Himonas CAA (1997) Survey on the prevalence of internal parasites of equines in Macedonia and Thessalia-Greece. Journal of equine veterinary science 17: 550-552. Link: https://goo.gl/xkYT6A

27. Sinasi U, Mustafa A (2009) A survey on helminth infections of equines in the central black Sea region, Turkey: Turkish Journal of Veterinary and Animal science 33: 373-378. Link: https://goo.gl/8prNUr

28. Urquhart MG, Armour J, Duncan LJ, Dunn ML, Jennings WF (1996) Veterinary parasitology. $4^{\text {th }}$ ed. black well 3-137. Link: https://goo.gl/qTWeaz

Copyright: () 2017 Andarge B, et al. This is an open-access article distributed under the terms of the Creative Commons Attribution License, which permits unrestricted use, distribution, and reproduction in any medium, provided the original author and source are credited. 